\title{
Meta
}

Journal des traducteurs

Translators' Journal

\section{LAfArga, Francisco \& Pegenaute, Luis (Eds.) (2015): Creación y traducción en la España del siglo XIX. Berna: Peter Lang, $488 \mathrm{p}$.}

\section{Juan Ramírez-Arlandi}

Volume 62, numéro 1, avril 2017

URI : https://id.erudit.org/iderudit/1040483ar

DOI : https://doi.org/10.7202/1040483ar

Aller au sommaire du numéro

Éditeur(s)

Les Presses de l’Université de Montréal

ISSN

0026-0452 (imprimé)

1492-1421 (numérique)

Découvrir la revue

Citer ce compte rendu

Ramírez-Arlandi, J. (2017). Compte rendu de [LAFARGA, FRANCISCO \& PEgenAute, LuIS (Eds.) (2015): Creación y traducción en la España del siglo XIX. Berna: Peter Lang, 488 p.] Meta, 62(1), 239-241.

https://doi.org/10.7202/1040483ar

Ce document est protégé par la loi sur le droit d'auteur. L'utilisation des services d'Érudit (y compris la reproduction) est assujettie à sa politique d'utilisation que vous pouvez consulter en ligne.

https://apropos.erudit.org/fr/usagers/politique-dutilisation/ 
Quand l'hégémonie tient par un régime de la mondialité, une poétique de la traduction -de l'intraduisible- aidera à rendre disponible le pouvoir de libération singulier qui se tient en tension dans la double force critique du langage: l'accélérateur d'histoire que constituent ensemble le poème et les langues, "en cela que plusieurs". (p. 305)

En conclusión, pues, cabe afirmar que Critiques de l'anglais. Poétique et politique d'une langue mondialisée presenta una profunda reflexión sobre la alteridad y la "poética de lo extranjero" desde una óptica influenciada eminentemente por los Estudios Culturales y el Poscolonialismo pero que bebe de muchas otras fuentes. Joubert da en este volumen una serie de reflexiones y explicaciones teóricas que permiten entender los retos que conlleva el fenómeno complejo de la globalización cultural.

Albert Morales Moreno Università Ca' Foscari Venezia, Venecia, Italia

Lafarga, Francisco \& Pegenaute, Luis (Eds.) (2015): Creación y traducción en la España del siglo XIX. Berna: Peter Lang, 488 p.

Fruto de la reconocida actividad editorial de los profesores Francisco Lafarga y Luis Pegenaute en el ámbito de la historia de la traducción y siguiendo el camino iniciado por Autores/traductores en la España del siglo XIX (2015), este volumen con el título homónimo del proyecto Creación y traducción en la España del siglo XIX (FFI2012-30781) presenta 31 trabajos de investigación en este campo firmados por 32 autores. Entre ellos destaca por su carácter más general el de Solange Hibbs, cuya atinada argumentación al respecto de la traducción como práctica de transferencia cultural interdisciplinar conlleva indefectiblemente la superación del binomio texto original/texto traducido y de los límites geopolíticos. A tal efecto, la autora formula una interesantísima batería de reflexiones en distintos epígrafes: las perspectivas epistemológicas relativas, por ejemplo, al giro cultural; el reconocimiento del estatus del traductor y su inserción en las diversas redes privadas y/o institucionales; los fundamentos metodológicos, referidos a la aportación de la historia; las propias traducciones, destacando los criterios de selección de los originales; los procesos, incluyendo los medios de difusión de las traducciones; las reflexiones sobre los actores, con especial mención a sus condiciones de trabajo y a otros aspectos como el plagio, los paratextos; y los fines de la traducción, en aras de evidenciar las diferencias interculturales.

Si bien en todos los capítulos subyace la reflexión acerca de los conceptos de autoría y traducción y sin descartar otras posibilidades, advertimos entre las distintas aportaciones ciertas similitudes temático-metodológicas a tenor de las secciones que Hibbs establece. Así, a través del análisis de la inserción de los traductores en las redes privadas y/o institucionales, María Jesús García Garrosa indaga acerca del traductor y crítico teatral José María Carnero y de las polémicas que se generaron en algunas revistas literarias de la época que ilustran la relación entre las convenciones teatrales contemporáneas y la oposición entre traducción fiel y adaptación. En la misma línea, el binomio autoría-traducción, el "giro ético" en el ámbito traductológico y los vínculos que el poeta Ventura Ruiz Aguilera mantuvo con el matrimonio Murguía-Castro constituyen el objeto del interesante estudio en el que María do Cebreiro Rábade Villar aborda la obra traductora de Rosalía de Castro.

La consideración de los fundamentos metodológicos, en especial, la relevancia de la historia para el estudio de la traducción queda patente en algunas contribuciones. El estudio de las traducciones "subversivas" de Walter Scott que vertió Pablo de Xérica permite a José Enrique García González documentar excepcionalmente cómo el traductor convierte sus "Prólogos" en espacios de confrontación ideológica y cómo determinadas estrategias textuales inciden en la relación entre "traducción, ideología y poder". En semejantes términos y a través del estudio de las adaptaciones teatrales al español de Uncle Tom's Cabin (1852) y Cora ou L'esclavage (1861) de Stowe y Barbier, respectivamente, Eva Lafuente explora con precisión cómo la escena española tardodecimonónica suavizó el mensaje abolicionista. Igualmente, Luis Pegenaute justifica acertadamente que determinadas traducciones de textos clásicos vertidas magistralmente resultan inadecuadas dependiendo del contexto socio-político y literario de la cultura meta, como sucedió con la representación en 1838 del Macbeth del periodista, escritor y traductor liberal José García de Villalta que, pese al respaldo inicial de la crítica, no disfrutó del favor del público de la época.

El vínculo entre traducción, crítica y creación guarda a su vez una estrecha relación con las traducciones y los criterios que rigen la selección de los originales. A partir de las traducciones que el poeta cordobés Guillermo Belmonte Müller vertió de Las noches de Alfredo de Musset (1882), Irene Atalaya desgrana la producción poética de Belmonte para incidir en la decisiva influencia que sus traducciones ejercieron sobre su labor creadora. El acercamiento de Juan F. García Bascuñana a la figura de Nemesio Fernández Cuesta desvela la influencia de su labor traductora de obras históricas sobre su propia producción, su 
fecunda actividad en el ámbito de la traducción literaria y cómo tal bagaje resultó decisivo en su quehacer lexicográfico. En su precisa semblanza del traductor teatral Isidoro Gil y Baus (1814-1866), José Luis González Subías reflexiona sobre la tenue distinción que el público de la época atisbaba entre autoría y traducción, máxime cuando la adaptación, muy del gusto del Romanticismo, constituía en sí misma un referente creador. De igual manera, Giovanna Fiordaliso analiza la relación entre la traducción que Galdós llevó a cabo en 1867 de The Posthumous Papers of the Pickwick Club (1836) de Dickens; un estudio crítico sobre el autor inglés; y, finalmente, su novela La Fontana de Oro (1870), para concluir que la actividad traductora se configura como un aprendizaje que posibilita una recreación entre el universo cervantino y el dickensiano. Tras la consideración de una serie de elementos formales y el análisis riguroso de los procedimientos de traducción, Francisco Lafarga, reflexiona en términos de "creación" u “originalidad" sobre la relación existente entre una obra de Laloue, Bourgeois y Laurent; un "disparate dramático" de traductor desconocido; $y$, en tercer lugar, una comedia de magia de Hartzenbusch. Miguel Ángel Muro prueba que la adaptación o “españolización” que Manuel Bretón de los Herreros preconizaba no halla refrendo en su versión de Los hijos de Eduardo (1835), en la que se decanta por la traducción literal y por una métrica variada alejada de la original. Concepción Palacios Bernal se interesa por la trayectoria de Amancio Peratoner como autor de novelas acerca de las relaciones extramatrimoniales y de la prostitución, y su afinidad argumental con las traducciones que vertió de novelas de Gautier, Flaubert y Zola. Carmen Ramírez Gómez, por su parte, estudia la obra y la figura de Alfredo Opisso y Viñas, destacado representante de la vida cultural catalana durante la segunda mitad del siglo XIX, que orientó su faceta de políglota traductor hacia aquellos autores y obras que habrían de enriquecerle intelectualmente. La descripción que Susana María Ramírez Martín presenta de las traducciones del padre de la "medicina social", Samuel Tissot, permite incidir en la vinculación de la actividad traductora con el desempeño profesional de la medicina, lo cual no resultó óbice para que en ocasiones los propios traductores enriqueciesen el original con sus propias "aportaciones" o "memorias".

El análisis de los procesos, con especial atención a los medios de difusión de las traducciones, suscita el interés de distintos colaboradores. En un estudio ampliamente documentado, M. ${ }^{\text {a }}$ del Rosario Álvarez Rubio presenta la labor de intermediación cultural que el semanario madrileño La Lectura para todos desplegó entre 1859 y 1861 incluyendo traducciones de distintos géneros a partir de diversas lenguas por una pléyade de traductores. Los trasvases entre obra poética propia y traducción vertebran el análisis de Ángeles Ezama Gil acerca de las versiones que Gertrudis Gómez de Avellaneda llevó a cabo de distintas composiciones del poeta luso Augusto José Gonçalves Lima y que, a la postre, le permitieron iniciar una fructífera colaboración con la Revista Peninsular. En el ámbito de La Vida Galante. Revista semanal ilustrada Marta Giné Janer repasa detalladamente la extensa nómina de autores españoles que reivindican los derechos de la mujer y su protagonismo en el progreso social, concluyendo que la elección de autores y originales viene determinada por su afinidad con los fines ideológico-culturales de la revista y los crematísticos de la editorial. En parecidos términos, Diana Muela Bermejo analiza cómo la revista de contenido satírico y humorístico Juan Rana acogió traducciones de escenas dialogadas breves y cuentos de escritores franceses en los que subyace una visión cómica de ciertos comportamientos masculinos. En su trabajo Begoña Regueiro Salgado ilustra cómo La Guirnalda, periódico conservador destinado al público femenino, sirvió de eficaz medio para introducir en el sistema literario español los cuentos de los hermanos Grimm y, subrepticiamente, "educar" al colectivo femenino en el ámbito familiar a través de las traducciones que apostaban por una estrategia decididamente naturalizadora. Finalmente, dos capítulos coinciden en el estudio de la trayectoria de la traductora Joaquina García Balmaseda (1837-1911): de un lado, Helena Establier Pérez disecciona la intensa actividad que Balmaseda desplegó en La Correspondencia de España con un claro compromiso con la literatura escrita por mujeres desde posiciones conservadoras; de otro, Dolores Thion Soriano-Mollá subraya la motivación comercial de la propia publicación y el pane lucrando para justificar la elección de autores y títulos, la autocensura y la adecuación/ recreación de las traducciones de Balmaseda.

En el ámbito de las reflexiones sobre los actores, Lieve Behiels estudia el prólogo a la traducción de Ramuntcho de Pierre Loti (1897), en el que Emilia Pardo Bazán confiesa sus gustos literarios para concluir que solo hasta cierto punto puede considerársele como un manifiesto literario en tanto que la visión de la autora no coincide con la de Loti. Pere Gifra-Adroher se interesa por la reseñable actividad como traductor de literatura religiosa y de novela gótica del sacerdote Luis Monfort, incidiendo en los prólogos en los que este enfatiza su interés moralizador en detrimento del gusto de los “traduccionistas". El análisis de los vínculos entre traducción y reescritura permite a Alicia Piquer Desvaux indagar en la figura de Juan Manuel de Berriozabal como traductor del poeta 
romántico Lamartine, posición que le permitió acometer posteriormente la reescritura del poema original La Cristiada (1611) del dominico Diego de Hojeda. Por su parte, Miguel Ángel Vega Cernuda y Elena Serrano Bertos estudian exhaustivamente la relación entre, de una parte, la tarea de traducción que se plasmó en el prólogo y en algunos pasajes en forma métrica de Juan Valera incluidos en la versión del Fausto de Guillermo English y, de otra, en su relato Las ilusiones del doctor Faustino, narración menor del autor cordobés que, empero, se concibe como una "variación sobre el tema fáustico". Finalmente, el estudio de la "Advertencia preliminar" que Menéndez y Pelayo antepone a la traducción de El mercader de Venecia incluida en los Dramas de Guillermo Shakespeare (1881) permite a Juan Miguel Zarandona analizar la recepción de la obra para, seguidamente, estudiar la traducción y rebatir los falsos estereotipos atribuidos al traductor.

Por último, un número significativo de capítulos versa sobre los fines de la traducción y la constatación de las diferencias interculturales (y, por supuesto, literarias) entre sistemas distintos. Al respecto de la llamada "novela fisiológica", Flavia Aragón Ronsano indaga en las traducciones de $\mathrm{La}$ fille Elisa (1877) de Goncourt haciendo hincapié en los cambios de título de las versiones que, no obstante, resultaron fallidas por su sesgo comercial y distanciamiento de la intención y estética original. En esta línea y como aconteció con la literatura gótica en España a comienzos del siglo XIX, Miriam López Santos da cuenta de cómo la traducción u otras prácticas cercanas como la adaptación impulsaron la incorporación de nuevos géneros al catálogo peninsular ya existente. Por su parte, Pedro Méndez escruta exhaustivamente la trayectoria de Rafael del Castillo como importador de literatura francesa centrándose en los cambios introducidos en la adaptación española de una obra de Balzac y en las técnicas traductológicas empleadas en su versión de una obra de Gautier. En el caso de Hermenegildo Giner de los Ríos y su traducción de Cuore (1886) de Edmondo de Amicis, Assunta Polizzi evidencia la instrumentalización de la labor traductora al servicio del ideal regeneracionista (aggiornamento) de la cultura española que se identificaba a la perfección con la propuesta krausista de progreso a partir de la educación.

A tenor de lo anterior podemos concluir que esta compilación de trabajos llevada a cabo por los profesores Francisco Lafarga y Luis Pegenaute constituirá en lo sucesivo una referencia imprescindible a la hora de explorar y profundizar en la historia de la traducción en España (e incluso en el ámbito hispano) en esta época. La inextricable relación entre traducción y autoría, las relaciones con autores y sistemas literarios europeos, la variedad de géneros abordados, la profundidad de los estudios y, por supuesto, los presupuestos metodológicos que comparte el conjunto de participantes en el volumen corroboran la afirmación de que España fue un país traductor durante el siglo XIX, con todas las implicaciones que esta aseveración conlleva en los más variados ámbitos de la historia literaria, científica, política y cultural.

JUAN RAmíreZ-ARLANDI Universidad de Málaga, Málaga, España 